CASE REPORT

\title{
Tension viscerothorax: an important differential for tension pneumothorax
}

\section{B McCann, A O'Gara}

Emerg Med J 2005;22:220-221. doi: 10.1136/emj.2003.008367

W describe a case of acute tension viscerothorax secondary to blunt vehicular trauma causing diaphragmatic rupture. With sufficient gastric herniation to cause mediastinal shift and haemodynamic compromise, the clinical presentation may mimic that of tension pneumothorax. Tension viscerothorax is not referred to in the Advanced Trauma and Life Support ${ }^{1}$ (ATLS) manual.

\section{CASE REPORT}

A 70 year old male pedestrian was struck by a fast moving motor vehicle. On arrival at a local community hospital he was haemodynamically stable with blood pressure, heart rate, and respiratory rate all within normal range. Positive examination and radiological findings included a right pubic ramus fracture, and an undisplaced right fibular fracture. Ten hours later he was transferred to a trauma facility for further management of his orthopaedic injuries.

During transfer the patient deteriorated and on arrival at the regional trauma facility the patients respiratory rate was 46/min, heart rate 132/min, and his blood pressure had fallen to $90 / 60$. His left hemithorax was hyper-resonant with absent breath sounds. Auscultation detected prominent bowel sounds in the left infraclavicular region.

A presumptive diagnosis with reference to his first chest radiograph (fig 1 ), of acute tension viscerothorax was made and confirmed with a portable chest radiograph (fig 2). The patient was given 100\% oxygen, a two litre bolus of crystalloid, and a nasogastric tube inserted, which promptly relieved his respiratory distress. Repeat chest examination showed improved air entry over the left hemithorax. The

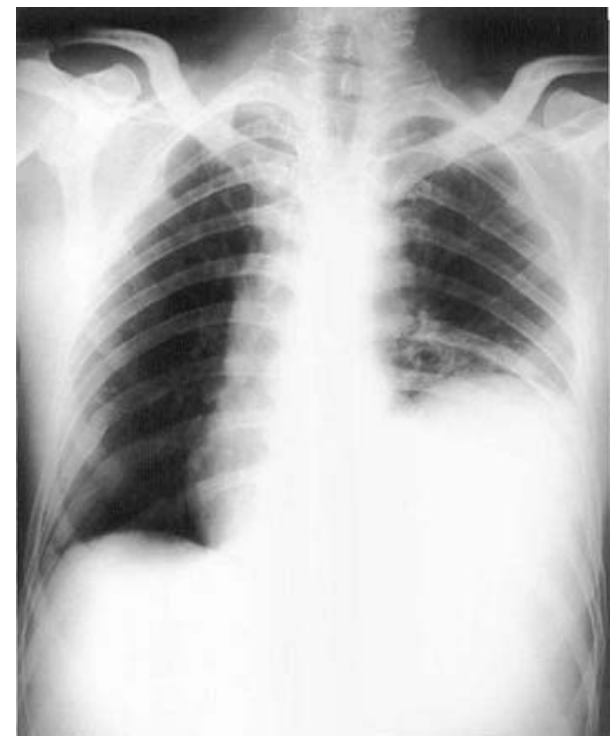

Figure 1 First chest radiograph of the patient. patient was removed to the operating theatre where a $7 \mathrm{~cm}$ tear in the left hemidiaphragm was oversewn. Of note at operation, the spleen and left kidney were uninjured and there was no evidence of pneumothorax or haemothorax. The patient's recovery was unremarkable.

\section{COMMENT}

Acute diaphragmatic injury is an uncommon complication of blunt or penetrating trauma to the chest or abdomen. ${ }^{2}$ Herniation of intra-abdominal viscus into the chest cavity with resultant tension viscerothorax is an exceedingly rare complication. Pathophysiologically, tension viscerothorax reduces venous return to the heart much like tension pneumothorax. ${ }^{2}$ Clinically, it may be difficult to differentiate the two conditions.

Diagnosis of diaphragmatic rupture depends on a high index of clinical suspicion and careful scrutiny of the chest radiograph. In this scenario the key clinical clue was the presence of bowel sounds high in the left hemithorax associated with an earlier chest radiograph that showed a raised left hemidiaphraghm. In an estimated $40 \%$ of cases careful examination of the chest radiograph will raise the suspicion of diaphragmatic rupture. Radiological features of the chest suggestive of diaphragmatic rupture include: gas bubble in the chest, nasogastric tube in the chest, elevated hemidiaphragm, irregular diaphragmatic outline, and compression atelectasis of the lower lobe. ${ }^{3}$

Assessing the value of computed tomography in the diagnosis of diaphragmatic rupture has been limited by small patient populations. A recent study suggests that helical computed tomography can detect $78 \%$ of left sided diaphragmatic ruptures and $50 \%$ of right sided ruptures. ${ }^{4}$ In the presence of herniated intra-abdominal viscera computed tomography was $100 \%$ accurate. Because most patients with diaphragmatic injuries will require computed tomography for evaluation of associated intra-abdominal injuries, helical computed tomography is seen to be the study of choice for

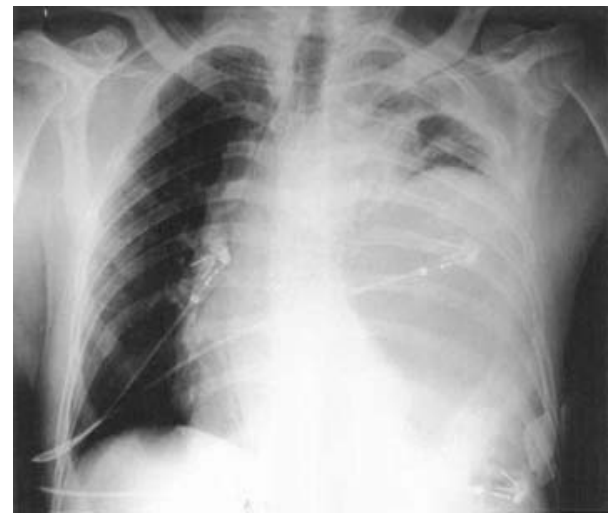

Figure 2 Portable chest radiograph confirming diagnosis of acute tension viscerothorax. 
visualisation of the diaphragm. In cases where doubt remains, magnetic resonance imaging is the gold standard. ${ }^{5}$ In the acute trauma situation with attendant monitoring equipment, magnetic resonance imaging may not be an option.

Nasogastric or orogastric tube decompression is the initial treatment of choice of tension viscerothorax, followed by definitive surgical repair. If tension pneumothorax is suspected and treated, thoracocentesis will add a pneumothorax (if not already present) and possible clinical deterioration. Tube thoracostomy could result in penetration of abdominal viscus with consequent spillage of gastric contents into the chest cavity.

Bag-mask support of ventilation should be avoided in tension viscerothorax. There is one reported case of clinical deterioration after nasogastric tube insertion. ${ }^{6}$ Direct percutaneous needle decompression of the distended stomach through the chest wall has been shown to be experimentally effective in a small cadaveric group. ${ }^{6}$

We recommend that tension viscerothorax be introduced in the ATLS differential for tension pneumothorax in cases of blunt chest trauma.

\section{Authors' affiliations}

B McCann, A O'Gara, Emergency Department, Waterford Regional Hospital, Ireland

Correspondence to: Dr B McCann, Emergency Department, Waterford Regional Hospital, Ireland; bmaccanna@hotmail.com

Accepted for publication 27 May 2004

\section{REFERENCES}

1 American College of Surgeons. Advanced trauma and life support manual. Chicago: American College of Surgeons, 1997.

2 Shah R, Sabanathan S, Mearns AJ, et al. Traumatic rupture of the diaphragm. Ann Thorac Surg 1995;60:1444-9.

3 Shapiro MJ, Heiberg E, et al. The unreliability of CT scans and initial chest radiographs in evaluating blunt trauma induced diaphragmatic rupture. Clin Radiol 1996:51:27-30.

4 Killeen KL, Mirvis SE, Shanmuganathan K. Helical CT of diaphragmatic rupture caused by blunt trauma. AJR Am J Roentgenol 1999; 173:1611-16.

5 Shanmuganathan K, Mirvis SE, White CS, et al. MR Imaging of hemidiaphragms in acute blunt trauma: experience with 16 patients. AJR Am J Roentgenol 1996;167:397-402.

6 Slater RG. Tension gastrothorax complicating acute traumatic diaphragmatic rupture. J Emerg Med 1992;10:25-30.

\title{
Irreducible volar dislocations of the proximal interphalangeal joint
}

\author{
N V Deshmukh, S V Sonanis, J Stothard
}

Emerg Med J 2005;22:221-223. doi: 10.1136/emj.2004.014514

$\mathrm{V}$ olar dislocations of the finger proximal interphalangeal joint (PIPJ) is a very rare injury. It is often missed in accident and emergency (A\&E) and is chronic and irreducible when first seen in the hand clinic. Intrarticular entrapment of the extensor tendon may render close reduction difficult. We report three cases, all sent home from the A\&E department, one in the thumb. A good outcome was obtained in these cases with early intervention.

\section{CASE 1}

A 20 year old athlete sustained a twisting injury to his left thumb while on a skiing holiday. He had the skiing stick in his left hand and the stick got stuck, his left thumb still being held in the leather loop of the stick sustaining this injury. On examination the interphalangeal joint (IPJ) was swollen and tender. Active flexion was possible but extension was weak and painful. Valgus stress was positive in extension. Radiographs showed mild subluxation of the IPJ. After attempts to close reduce the IPJ failed open reduction was performed. The ulnar collateral ligament was ruptured completely and on valgus stressing the extensor tendon was seen entrapped in S shaped in the IPJ (fig 1). A hook was inserted pulling the tendon and the joint was reduced. The capsule and the collateral ligament was repaired. The thumb was immobilised in 20 degrees of flexion. After two weeks mobilisation was started. This patient made an uneventful recovery.

Abbreviations: PIPJ, proximal interphalangeal joint; IPJ, interphalangeal joint
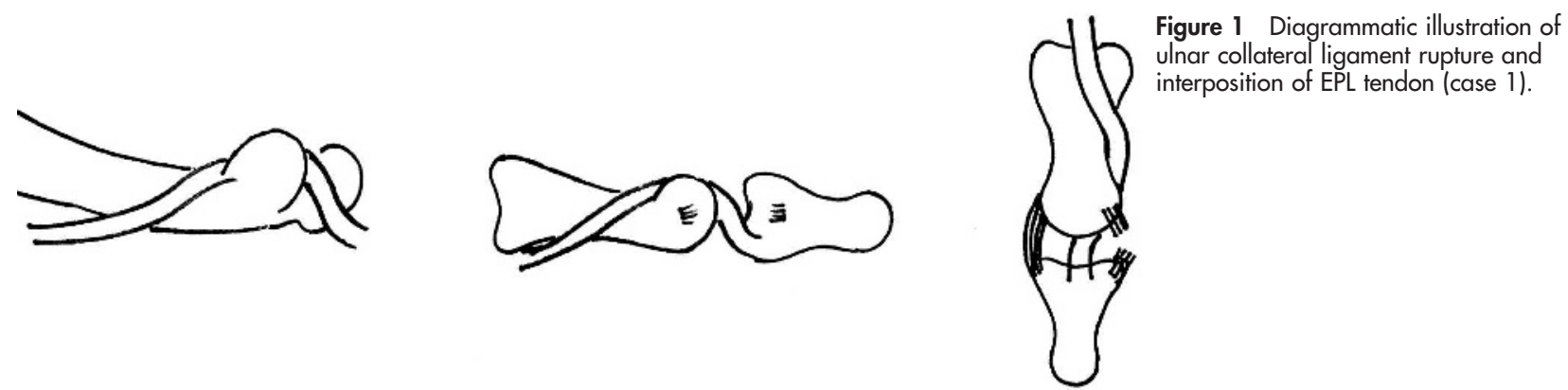

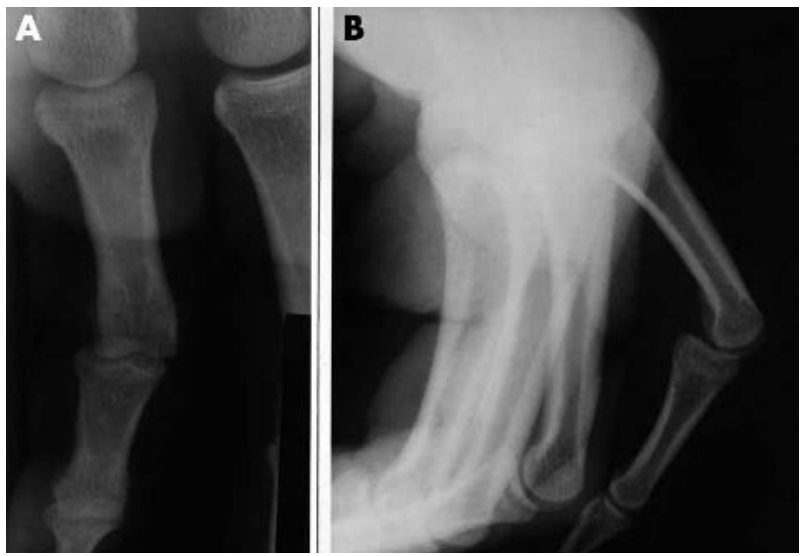

Figure 2 Preoperative radiographs showing mild volar subluxation of the PIPJ of the index finger (case 2).

\section{CASE 2}

A 28 year old carpenter was referred two days after injury with pain, swelling, and deformity in his right middle finger. He was struck with the ball while playing volleyball and probably sustained a severe twisting injury. He immediately felt sudden, sharp, shooting pain in his middle finger. He was seen in A\&E where no definite bony injury was noted and buddy tapping was applied. The patient returned to A\&E the next day unable to cope with the pain and was referred to the hand surgeons. Radiographs showed volar subluxation of the PIPJ. The volar subluxation could be reduced but the finger was unstable and immediately sprung back to subluxed position when left unsupported. On exploration a longitudinal tear was present in the extensor expansion between the central slip and the lateral band with the proximal phalanx protruding through the tear. Reduction was easy once the tear was closed with a continous 4/0 PDS suture (making sure that it was not too tight and that full flexion was still possible). The joint was stable and did not dislocate. At two weeks the finger was mobilised with a good functional result.

\section{CASE 3}

A 38 year woman sustained injury to her right index finger. She had attempted removing washed clothes while the washing machine was still slowing down. She felt sudden pain in her right index finger as it got stuck in the hole of the moving drum. She was seen in A\&E, buddy tapping was
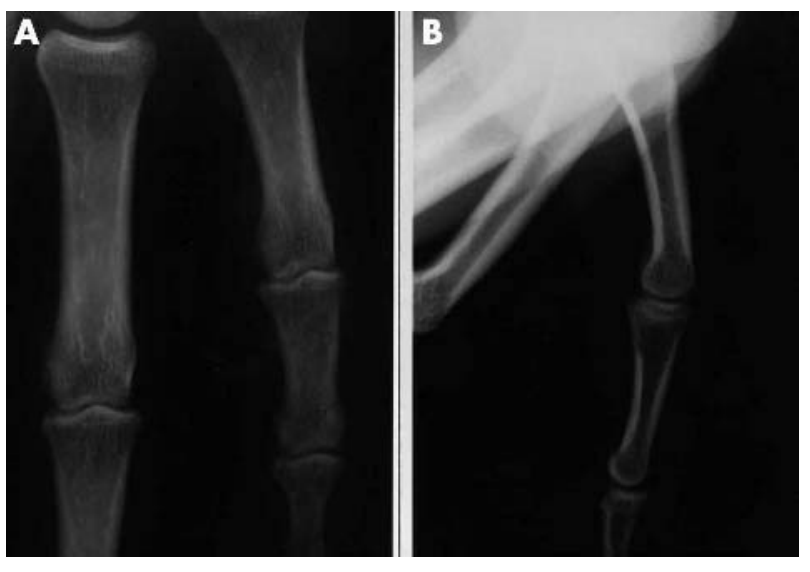

Figure 3 Postoperative radiograph showing restoration of subluxation at PIPJ of the index finger (case 2).

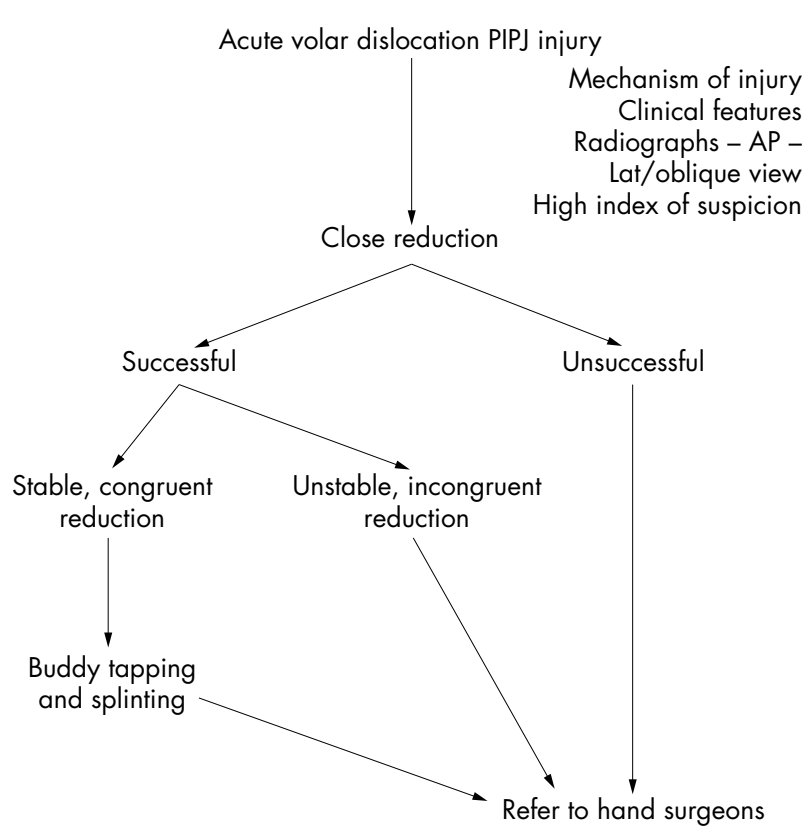

Figure 4 Schematic diagram for acute volar dislocation PIPJ injury.

applied. The patient returned to A\&E the next day and was referred to the hand surgeons with a suspicion of compartment syndrome of the finger. The right index PIPJ was swollen, tender, and held in slight flexion. End on view of the finger was deformed. Any attempt to straighten the finger passively or actively was met with apprehension. Radiographs (fig 2) showed volar subluxation of PIPJ. On exploration the central extensor tendon although intact was entrapped in the PIPJ. The longitudinal tear in the extensor apparatus was repaired. The follow up was uneventful (fig 3).

\section{DISCUSSION}

The PIPJ is one of the most commonly injured joints in the hand. ${ }^{1}$ Dislocations of the PIPJ of the hand are comparatively common injuries. Three types of PIPJ dislocations have been described: lateral, dorsal, and volar (rotatory). ${ }^{2}$ Dorsal and lateral dislocations can usually be reduced in a closed fashion.

Volar (complex rotary) dislocations are rare and uncommon injuries. They are commonly irreducible by closed methods. ${ }^{3}$ These injuries are often missed in A\&E and misdiagnosed resulting in delayed treatment and permanent impairment. Early detection, aggressive management, and rehabilitation to avoid significant morbidity is essential. ${ }^{5}$

The deforming force in these injuries is an axial compression with simultaneous rotational element. Further axial loading and rotational tear leads to opening of the joint as a result of the rotation of the condyles and brings the lateral band of the extensor tendon on the volar side under the head of the proximal phalanx. Once this deforming force is passed off, the finger returns back to a so called normal position but the extensor tendon remains entrapped in the joint. The central slip may remained attached to the middle phalanx or it may become avulsed with or without a fragment of bone. ${ }^{6}$ This unicondylar proximal phalangeal head notwithholding through an area through the lateral band and the central slip is a major cause preventing successful closed reduction. ${ }^{7}$ Closed reduction can also be blocked as a result of entrapment of the volar plate, ${ }^{8}$ avulsed central sleeve, ${ }^{9}$ lateral band, ${ }^{10}$ or a displaced articular fracture fragment. ${ }^{11}$ 
On clinical examination of volar PIPJ injuries, the joint appears flexed with the distal and the middle phalanges deviated to one side. ${ }^{6} \mathrm{~A}$ true lateral radiograph is diagnostic demonstrating an oblique orientation of the middle phalanx and lateral view of the proximal phalanx. Resistance to passive flexion and extension may exist and therefore, careful evaluation of the joint is important to spot the difference between active and passive range of movements, which, in a reduced finger, might indicate loss of central slip function. It is important to determine if the lesion is acute or chronic since the age of the injury will guide the management.

Acute injuries do well if recognised and treated early (fig 4). Late reconstruction of these injuries is technically difficult and often unrewarding. The treatment results are often poor and are particularly related to failure in recognising the rotatory component of the injury and subsequently estimating the degree of instability and the extent of the soft tissue damage.

The complication of these injuries are loss of movements, a chronic laxity, pain, swelling, deformity, and a fixed flexion contracture is common when aggressive attempts to achieve full extension are not undertaken. ${ }^{12}$

Most cases in the literature are isolated reports. ${ }^{14}{ }^{15}$ This itself speaks of the rarity of this condition. We report three cases of similar injuries.

All the reported cases were sent home from the A\&E. They returned within a week to the hand clinic with a deformed tender swollen finger, two of them returned, unable to bear the pain. As these are extremely rare injuries a good clinical history and examination is necessary. It may not always be possible to acquire the detailed mechanism of injury especially in a busy A\&E department. Clinical examination in an acute painful situation needs a lot of patience and perseverance to locate the exact cause and nature of a closed finger injury. Severe apprehension and lack of cooperation from the patient in an acute setting might also be responsible for these injuries to be missed initially. All these cases required open reduction. Early referral, within the first week, to the hand clinic is essential in a suspected case. If diagnosed late and therefore treated late the final outcome and function is compromised.
We believe that it is extremely important to be aware of this injury. Any passive painful flexion or extension of the finger PIPJ should raise a suspicion. High index of suspicion, awareness and early referral to a hand clinic, subsequent repair and rehabilitation gives a good functional outcome.

\section{Authors' affiliations}

N V Deshmukh, S V Sonanis, J Stothard, Accident and Emergency Department, North Tees General Hospital, UK

Correspondence to: $\operatorname{Dr} N$ V Deshmukh, 8 Albert Street, Haverfordwest SA61 1TB, UK; deshmukh_nitin@hotmail.com

Accepted for publication 19 January 2004

\section{REFERENCES}

1 Burton RI, Eaton RG. Common hand injuries in the athelete. Orthop Clin North Am 1973;4:809-38.

2 Eaton RG, Littler JW. Joint injuries and their sequelae. Clin Plast Surg 1976:3:85-98.

3 Thompson JS, Eaton RG. Volar dislocation of the proximal interphalangeal joint. J Hand Surg 1977;2:232.

4 4.Posner MA, Wilenski M. Irreducible volar dislocation of the proximal interphalangeal joint of the finger caused by interposition of the intact central slip. J Bone Joint Surg [Am] 1978;60:133-4.

5 Benson LS, Bailie DS. Proximal interphalangeal joint injuries of the hand. Part 2. Treatment and complications. Am J Orthop 1996;25:527-30.

6 Benson LS, Bailie DS, Marymont JV. Proximal interphalangeal joint injuries of the hand. Part 1. Anatomy and diagnosis. Am J Orthop 1996;25:474-7.

7 Moberg E. Fractures and ligamentous injuries of the thumb and fingers. Surg Clin North Am 1960;40:297-309.

8 Oni O. Irreducible buttonhole dislocation of the proximal interphalangeal joint of the finger. J Hand Surg [Br] 1985;10:100.

9 Selig S, Schien A. Irreducible buttonhole dislocations of the fingers. J Bone Joint Surg 22:436-41.

10 Johnson FG, Greene MH. Another case of irreducible dislocation of the proximal interphalangeal joint of the finger. J Bone Joint Surg 48A:542-4.

11 Whipple TL, Evans JP, Urbaniak JR. Irreducible dislocation of a finger joint in a child. J Bone Joint Surg 62A:823-33.

12 Kiefhaber TR, Stern PJ. Fracture dislocations of the proximal interphalangeal joint. J Hand Surg [Am] 1998;23:368-80

13 Freiberg A, Pollard BA, Macdonald MR, et al. Management of proximal interphalangeal joint injuries. J Trauma 1999;46:523-8.

14 Wang KC, Hsu KY, Shih CH. Irreducible volar rotatory dislocation of the proximal interphalangeal joint. Orthop Rev 1994;23:886-8.

15 Inove G, Maeda N. Irreducible palmar dislocation of the proximal interphalangeal joint of the finger. J Hand Surg [Am] 1987;12:1077-9.

\section{Low cost, high risk: accidental nutmeg intoxication}

\section{A K Demetriades, P D Wallman, A McGuiness, M C Gavalas}

Nutmeg poisoning is rare but probably underreported and should be considered in recreational substance users with acute psychotic symptoms as well as central nervous system neuromodulatory signs that may mimic in part an anticholinergic hyperstimulation.

W report an accidental intoxication during voluntary ingestion of nutmeg. This occurred with a newly reported method for preparation of the mixture during an attempt for a low cost alternative to recreational drug use. Because of a recent second fatality with such misuse, nearly a century after the first one, and because of the suspected underreporting of the incidence of such episodes, the symptomatology and aetiology of myristicin intoxication is reviewed.

\section{CASE REPORT}

A previously well 18 year old student presented with complaints of palpitations, drowsiness, nausea, dizziness, thirst, and dry mouth. She was very anxious, restless, and agitated and described being "in a trance state". She specifically felt "like Jack in the box wanting to get out" but did not have hallucinations. She did not complain of urinary or abdominal discomfort and gave no history of 
seizures or migraine. She had an unremarkable medical and psychiatric history and denied any suicidal ideation. The patient refused to give any information regarding recreational drug use.

On examination the patient was agitated but alert, flushed but apyrexial, with a respiratory rate of 20/minute and saturation of $96 \%$ on room air. She was tachycardic at 102/ minute with a blood pressure of 105/68. Cardiopulmonary examination was unremarkable. The abdomen was soft and non-tender. Cranial nerves were normal, while peripheral nervous system examination showed brisk, symmetrical deep tendon reflexes. There was no neck stiffness. Pupils were dilated to size $4 \mathrm{~mm}$ and were symmetrically brisk to light and accommodation.

A 12 lead ECG showed a fast sinus arrhythmia (rate 95110/minute) with no ischaemic or hypertrophic changes. Serum urea, electrolytes, liver transaminases, full blood count, and urgent catecholamines were normal. Serum and urine toxicology screens were negative.

In view of the complexity of her condition she was admitted and five hours later admitted to having taken a large dose of nutmeg while trying to "get high". Some $50 \mathrm{~g}$ of commercially available grated nutmeg were blended into a milkshake, the patient drinking three quarters of the amount. A feeling of elation was experienced by at least two people, but in our patient this was followed by her presenting symptoms 30 minutes after ingestion.

The patient was kept for observation, offered reassurance, and rehydration. After symptoms had resolved she was allowed to return home 10 hours after presentation, 16 hours after ingestion.

\section{DISCUSSION}

Nutmeg intoxication has scantily been reported in the literature. Such reports span the period between 1908 and present day, although some claim that the first reported evidence of its effects was reported by Lobelius in $1576 .^{12}$ Most cases concern attempts to achieve an euphoric and hallucinogenic state at low cost. Previous reports include ingestion of grated or whole nutmegs, mixing of the spice with coffee, vodka or other alcohol, and concurrent use with cannabis. This time the method reported of blending within a milkshake, although novel simply illustrates the ingenuity of the people in search of a low cost "buzz". Nutmeg is an easily obtainable household item, originally imported from the Caribbean spice islands. It is known to have medicinal benefit as an antidiarrhoeal agent in selected cases $^{3}$ but also as an emmenagogue, carminative, and abortifacient agent. ${ }^{4}$ Attempts at nutmeg induced euphoria are said to have been common in the "hippie culture" of the 1960s and 1970s. It has also been reported in drug addicts, prisoners, adolescents, and college students where it is regarded an affordable alternative to limited supplies of ethanol and recreational drugs.

Although misuse is voluntary, intoxication is invariably accidental. There have been two fatal "overdoses" in the medical literature. The first was reported in the beginning of the 20th century involving about $14 \mathrm{~g}$ in an 8 year old. ${ }^{5}$ The second was reported in the beginning of the 21 st century and involved a 55 year old. ${ }^{6}$ Such a risk a century on is a timely reminder of the importance of this differential diagnosis when others have been excluded and when the patient could fit into an exposure category. Our patient was a higher education student who visited London for an entertainment weekend. As it was admitted, a group of people had tried and recommended a "nutmeg high". As such, the incidence of its misuse, especially in thrill seeking but low cost living students, is underreported and the possibility of intoxication must always be entertained.
How does nutmeg exert its effects? The active substance is myristicin, the volatile oil of the spice comprising a mixture of allylbenzene derivatives and terpines. ${ }^{7}$ Myristicin has a weak monoamine oxidase inhibitor action and with elemicin may be metabolised to an amphetamine-like compound with hallucinogenic effects similar to lysergic acid diethylamide. Other components of myristicin (linalool, safrol, isoeugenol, and eugenol) are structurally similar to serotonin agonists that may explain the cardiovascular response. ${ }^{8}$ The anxiogenic effect encountered in the feeling of impending doom has been linked to the serotonergic and GABAergic activity found in trimyristin, an extract of the Myristica fragrans seeds.'

Symptoms predominantly involve the central nervous and cardiovascular systems. In the former one may experience anxiety, fear, and a feeling of impending doom. Acute psychotic episodes, detachment from reality, like with "Jack in the box", may occur as can visual hallucinations, taking the form of time, colour, or space distortions. Patients may be hostile, combative, and agitated. Chronic psychosis with prolonged use has been reported. ${ }^{10}$ Cardiovascular manifestations include tachycardia, which may be the only finding on examination, palpitations, hypertension, and rarely hypotension and shock. ${ }^{11}$

Further symptoms are dry mouth, facial flushing, nausea, unsteadiness, epigastric pain, urinary retention, and blurred vision. Although it has been reported that a useful differentiating sign from anticholinergic intoxication such as belladonna alkaloids or atropine poisoning is that myristicin may cause miosis and not mydriasis, ${ }^{12}$ there is no conclusive evidence. In a review studying pupillary responses specifically, ${ }^{13}$ similar numbers of patients had dilated, constricted, or even unaffected pupils. While early miosis may be followed after a few hours by mydriasis, in some cases miosis was persistent 13 hours after ingestion whereas mydriasis was present from five hours. Experiments on cats failed to produce a local mydriatic action. Pupillary signs therefore are not necessarily reliable in the diagnosis of nutmeg poisoning.

Symptoms usually appear three to eight hours after ingestion and resolve within a day or two. Treatment is mainly supportive, although cases have been admitted to intensive care units, ${ }^{2}$ and should include cardiorespiratory monitoring for at least eight hours after ingestion (personal communication, Guy's Hospital Medical Toxicology Unit). The patient needs regular reassurance in view of the conquering feelings of anxiety, fear, and impending calamity. Sedation with benzodiazepines can be used to calm the patient and help reverse the amphetamine-like effects. Charcoal may help decrease systemic absorption; induction of emesis is controversial. ${ }^{14}$

Although the risks of nutmeg intoxication after voluntary use are not unknown to the medical community, certain groups of the population are still likely to experiment for low cost recreational drug alternatives. The presentation of acute psychotic symptoms accompanied by central nervous system neuromodulatory signs should alert the physician to this rare but probably underreported possibility especially in urban areas known to attract recreational substance users.

\section{Authors' affiliations \\ A K Demetriades, P D Wallman, A McGuiness, M C Gavalas, Department of Accident and Emergency, University College London Hospital, London, UK}

Correspondence to: $\operatorname{Dr}$ A K Demetriades, Department of Accident and Emergency, University College London Hospital, London WC1E 6AU, UK; andreas.demetriades@doctors.org.uk

Accepted for publication 4 March 2003 


\section{REFERENCES}

1 Cushny AR. Nutmeg poisoning. Proc Roy Soc Med 1908;1:39-44.

2 Sjoholm A, Lindberg A, Personne M. Acute nutmeg intoxication. J Intern Med 1998;243:329-31.

3 Barrowman JA, Bennett A, Hillenbrand P, et al. Diarrhoea in thyroid medullary carcinoma: role of prostaglandins and therapeutic effect of nutmeg. BMJ 1975;3:11-12.

4 Painter JC, Shanor SP, Winek CL. Nutmeg poisoning-a case report. Clin Toxicol 1971;4:1-4.

5 Cushny AR. Nutmeg poisoning. Proc Roy Soc Med 1908;1:39-44.

6 Stein U, Greyer H, Hentschel H. Nutmeg (myristicin) poisoning-report on a fatal case and a series of cases recorded by a poison information centre. Forensic Sci Int 2001;118:87-90.
7 Shulgin AT. Possible implication of myristicin as a psychotropic substance. Nature 1966;210:380-4.

8 Truitt EB Jr. The pharmacology of myristicin and nutmeg. Psychopharmacol Bull 1967;4:14.

9 Sonavane GS, Sarveiya VP, Kasture VS, et al. Anxiogenic activity of Myristica fragrans seeds. Pharmacol Biochem Behav 2002;71: 239-44.

10 Brenner N, Frank OS, Knight E. Chronic nutmeg psychosis. J R Soc Med 1993;86:179-80.

11 Green RC Jr. Nutmeg poisoning. JAMA 1959:171:1342-4.

12 Payne RB. Nutmeg intoxication. N Engl J Med 1963;269:36-8

13 Ahmad A, Thompson HS. Nutmeg mydriasis. JAMA 1975;234:274.

14 Abernethy MK, Becker LB. Acute nutmeg intoxication. Am J Emerg Med 1992; 10:429-30.

\section{Atlas: standard diagnostic tests for an unusual fracture}

\section{S Leigh-Smith, R Price, D Summers}

Emerg Med J 2005;22:225-226. doi: 10.1136/emj.2003.008516

The case is reported of an unusual atlas fracture with no reports of such an injury in the literature. The diagnosis of this injury emphasises the importance of simple clinical decision instruments, and systematic interpretation of investigations.

A 28 year old man who was 5 feet 9 inches and 16 stone was playing rugby as a number 8 . He ran head first into a tackle, causing an axial compression injury to his neck. This caused immediate, dull pain over the whole of his neck. He attempted to continue playing but found that merely running exacerbated the pain considerably. He later noticed the pain localising to the whole axial area along with his head "feeling heavy and loose". He self treated with a soft collar for two days, before presenting to the accident and emergency (A\&E) department, by which time the pain was persistent in the sub-occipital area. At no stage did he have any neurological symptoms.

Examination showed painful neck movements, with pronounced reduction of range in all directions.

Cervical spine radiography showed considerable retropharyngeal soft tissue swelling in the upper cervical spine (fig 1). The AP dens view showed subtle asymmetry of the atlantoaxial joints, with minor lateral displacement of the $\mathrm{Cl}$ lateral mass on the right (fig 2).

His neck was immobilised, and he was transferred to the regional neurosurgical service. Review of the cervical spine radiograph showed an unusual vertical lucency projected over the dens, and computed tomography of this area was performed (fig 3). The appearances suggested a congenital midline cleft atlas, with diastasis of the anterior synchondrosis.

The patient's neck was immobilised in an Aspen collar cervical orthosis. Ten days after the injury, he was brought back for flexion and extension radiographs of his neck, which showed no abnormal movement. He remained neurologically intact and external bracing was continued for eight weeks. Follow up computed tomography showed persistence of the $\mathrm{Cl}$ cleft but resolution of the retropharyngeal swelling. The flexion and extension views were repeated and no abnormal movement was detected. Physiotherapy was started to rebuild his range of neck movements and treat residual discomfort. Given the developmental anomaly of $\mathrm{Cl}$, he was advised to stop taking part in contact sports.

\section{DISCUSSION}

Screening for potentially unstable cervical spine injury starts with the use of a proven clinical decision instrument to determine who needs a cervical spine radiograph. ${ }^{1}$ If radiography is required the ATLS system of cervical spine radiological interpretation or similar ${ }^{3}$ should be used.

In this case the patient clearly had a suggestive history and abnormal examination requiring radiography. The

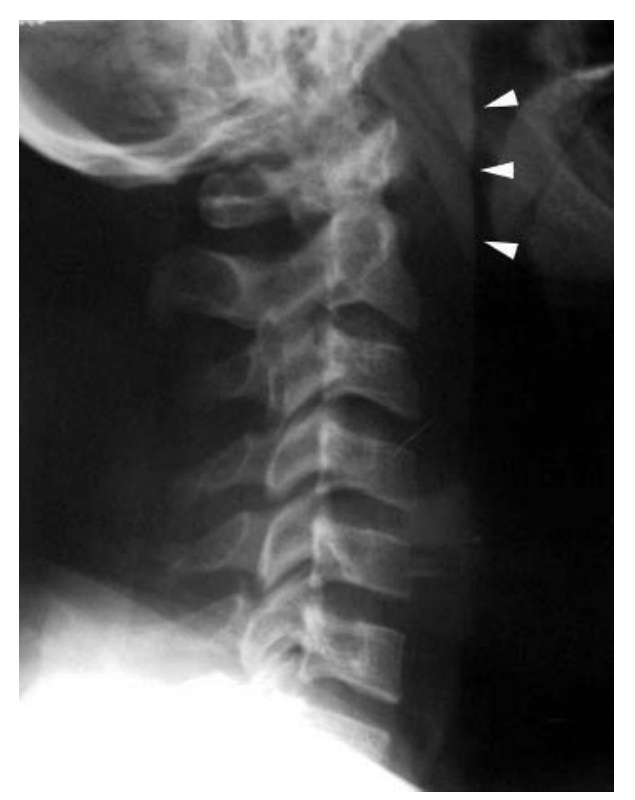

Figure 1 Lateral cervical radiograph with considerable retropharyngeal soft tissue swelling anterior to the upper cervical vertebrae (arrowheads). 


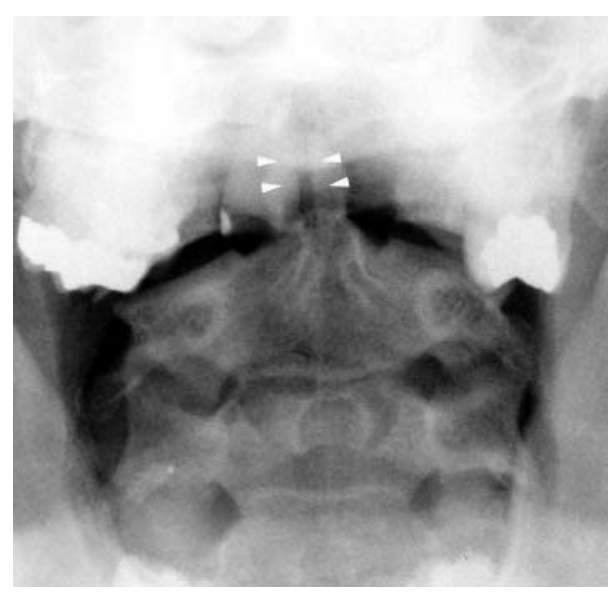

Figure 2 AP open mouth radiograph of $\mathrm{Cl} / \mathrm{C} 2$ showing vertical lucency projected over peg (arrowheads).

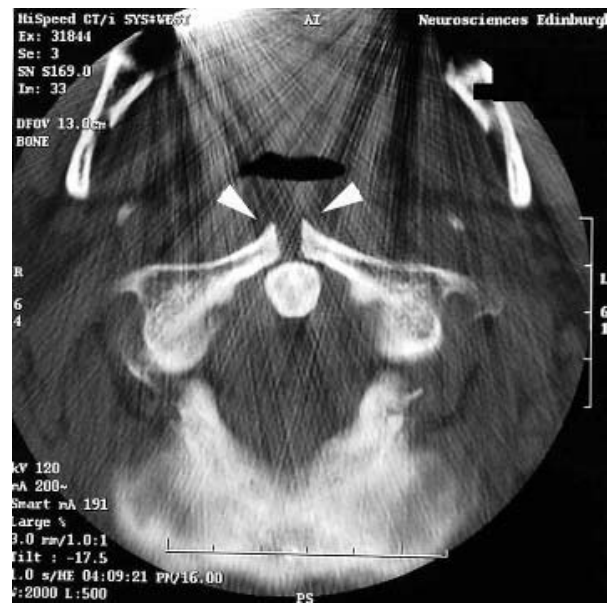

Figure 3 Axial fine section $\mathrm{CT}$ through $\mathrm{Cl}$ ring showing $\mathrm{Cl}$ anterior arch midline cleft with diastasis (arrowheads). The streak artefact is due to dental amalgam.

pronounced retropharyngeal swelling was sufficient to institute immobilisation and further specialist review.

Atlas fractures represent about $6 \%$ of cervical spine fractures. ${ }^{5}$ Different patterns were originally described by Jefferson, ${ }^{6}$ ranging from a fracture through one part of the ring to a complete burst fracture. Only 10 cases of paediatric atlas fractures have been reported, ${ }^{7}$ tending to pass through the fibrocartilagenous tissue between one of the three ossification centres. ${ }^{7-10}$ Ossification is usually complete by age 8 years, ${ }^{11}$ but incomplete ossification can occur $(0.33 \%-$ $5 \%$ of adults depending on position within the atlas) and lead to a persistent synchondrosis. ${ }^{79}$ Midline anterior atlas cleft is an unusual developmental anomaly, found in only $0.1 \%$ of adults in a necropsy study. ${ }^{12}$ It is usually associated with a midline posterior cleft. By analogy with the paediatric cases, a persistent synchondrosis in an adult may represent a weak point in the $\mathrm{Cl}$ ring and therefore be prone to disruption during axial compression loading. Although it is well known that congenital anomalies in the $\mathrm{C} 1 / 2$ region can be mistaken radiologically for new fractures we feel that the suggestive injury mechanism, symptomatology, prevertebral swelling, lateral mass displacement, apparent angulation at the anterior synchondrosis, and the subsequent improvement all point to an acute disruption of this patient's anterior synchondrosis. The expectation was that this injury was stable and could be managed with external bracing. This was reinforced by the minimal lateral displacement of the right $\mathrm{Cl}$ lateral mass (more than $7 \mathrm{~mm}$ indicates potential instability ${ }^{5}$ ), the flexion-extension views, and the patient's subsequent clinical course.

In both adult and paediatric age groups, neurological injury is unusual, because of the favourable proportions of the cord and canal in the upper cervical spine.

Most atlas injuries are considered stable and are managed conservatively with external bracing, although instability requiring internal fixation can occur if the transverse ligament of the dens is disrupted. Hence, A\&E practitioners should consider all these injuries as unstable.

\section{CONCLUSION}

Significant cervical spine injury is a statistically unusual finding in $\mathrm{A} \& \mathrm{E}$, but the thought of missing one is enough to bring most practitioners out in a cold sweat. This case shows that appropriate use of a clinical system of examination and radiological interpretation works. It also emphasises the importance of looking for retropharyngeal soft tissue swelling in cervical spine radiographs, which may be the only clue to significant cervical trauma.

\section{Authors' affiliations}

S Leigh-Smith, Defence Medical Services, Gosport, UK

R Price, Department of Clinical Neurosciences, Western General Hospital, Edinburgh, UK

D Summers, Department of Neuroradiology, Western General Hospital

Correspondence to: Mr S Leigh-Smith, c/o Monckton House, Alverstoke, Gosport PO12 2DL, UK; simonlsuk@aol.com

\section{REFERENCES}

1 Hoffman JR, Mower WR, Wolfson AB, et al. Validity of a set of clinical criteria to rule out injury to the cervical spine in patients with blunt trauma. NEngl J Med 2000;343:94-9.

2 American College of Surgeons. Advanced trauma life support. 6th ed. Chicago: ACS, 1997.

3 Raby N, Berman L, Lacey G. Accident and emergency radiology-a survival guide. London: WB Saunders, 1999:104-25.

4 Nicholson DA, Driscoll PA. ABC of emergency radiology. Cambridge: BMJ Books, 85-94.

5 Meyer PR Jnr, Bridwell KH, DeWald RL. The textbook of spinal surgery. Philadelphia: Lippincott-Raven, 1997:1679-741.

6 Jefferson G. Fracture of the atlas vertebra-report of four cases and a review of those previously recorded. Br J Surg 1920;7:407-11.

7 Judd DB, Liem LK, Petermann G. Paediatric atlas fracture: a case of fracture through a synchondrosis and review of the literature. Neurosurgery 2000;46:991-5.

8 Marlin AE, Williams GR, Lee JF. Jefferson fractures in children. J Neurosurg 1983;58:277-9.

9 Galindo MJ Jr, Francis WR. Atlantal fracture in a child through congenital anterior and posterior arch defects: a case report. Clin Orthop 1983;178:220-2.

10 Mikawa $Y$, Watanabe $R$, Yamano $Y$, et al. Fracture through a synchondrosis of the anterior arch of the atlas. J Bone Joint Surg 1987;69:483.

11 Williams PL, ed. Grays anatomy-ossification of the vertebral column. 38th ed. Edinburgh: Churchill Livingstone, 1995:532-3.

12 Geipel P. Zur kenntnis der spaltbildungen das Atlas und Epitropheus. Zentralb/ Allg Pathol 1955;94:19-84. 


\title{
Descending necrotising mediastinitis: a report of misdiagnosis as thoracic aortic dissection
}

\author{
S-L Chou, C-H Chern, J-D Chen, C-K How, L-M Wang, C-H Lee
}

Emerg Med J 2005;22:227-228. doi: 10.1136/emj.2003.006189

Descending necrotising mediastinitis is an uncommon disease in the emergency department. Early recognition is important for a good prognosis for this fatal condition. This report describes a case of a healthy 79 year old woman who was seen in the urgent care centre with the initial presentation of chest pain. Misdiagnosis was made because of the misreading of a flap-like artefact over the ascending aorta and difficulty interpreting subtle change of mediastinal soft tissue infiltration. The patient was then treated as dissecting aneurysm over ascending aorta until her condition deteriorated. Although aggressive treatment comprising thoracotomy, cervical incision and drainage, and antibiotics were begun, the response was poor. Emergency physicians should be familiar with this rare but highly lethal disease. Correlation should be made in a patient complaining about chest pain, especially combined with fever, sore throat, dysphagia, or neck swelling.

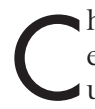
hest pain is a commonly encountered symptom in the emergency department (ED). Clinicians in the ED usually focus on the cardiovascular causes of chest pain. In this report, we present a case of descending necrotising mediastinitis (DNM) attributble to tonsillar infections, which was misdiagnosed as dissecting aneurysm initially. Reviewing the literature, there has been only one report of DNM from dental infection in the emergency medicine literature. ${ }^{1}$ Although chest pain is a frequent manifestation of oropharyngeal or deep neck infection with extension to chest, ${ }^{1-7}$ emergency physicians usually focus on more common causes of chest pain and are unfamiliar with this rare but highly mortal and morbid disease. We present her clinical picture and, through literature review, discuss the clinical pitfalls for this case.

\section{CASE REPORT}

The patient was a 79 year old woman, who came to our ED with complaints of chest pain, dysphasia, and general weakness for days. Five days before her transferral to our ED, she was sent to a regional teaching hospital ED because of severe chest pain. With a negative result for electrocardiogram, normal cardiac enzyme activity, and somewhat mild wide mediastinum, her severe chest pain led the physicians to put the aortic dissection into the differential diagnoses list. Initial contrast enhanced computed tomography (CT) of her chest revealed a "flap" over the ascending aorta (while some increased infiltration and minimal fluid accumulations over mediastinal fat surrounding her tracheal, carina, and oesophagus were neglected) (fig 1) and aortic dissection was diagnosed. She was sent to the intensive care unit for continuous monitoring, mainly for the blood pressure and pain control. During her stay in the intensive care unit, her chest pain subsided partially but she became weaker and had a swallowing problem. Under the impression of exacerbation of her dissection, she was transferred to our hospital for further evaluation and treatment. Tracing her history, she had only a resection of skin tumour over her leg with an uneventful consequence. Reviewing the clinical course before and during her stay in that teaching hospital, we found she had a fever and "common cold" before the admission and progressive dysphagia and sore throat during hospitalisation. At our ED, physical examination showed that she was clear with stable vital signs but had mildly acute distress. A throat examination showed mild right tonsillar enlargement with pus discharge and a neck examination showed no pronounced swelling or tenderness. Findings for the rest of the physical examination were unremarkable. Our blood tests showed mild leucocycytosis and a high $\mathrm{C}$ reactive protein $(290 \mathrm{mg} / \mathrm{l})$. An arterial blood gas analysis showed mild hypoxia $\left(\mathrm{PO}_{2} 67 \mathrm{~mm} \mathrm{Hg}\right)$. A chest radiograph had severe mediastinal widening, especially over the right superior region. Because of concern about the worsening of clinical conditions, contrast enhanced CT of her neck and chest was repeated and showed soft tissue swelling of her right tonsil with ill defined multi-loculated abscesses over the peritonsillar and retropharyngeal spaces, with downward extension into superior mediastinum (fig 2). Under the diagnosis of mediastinitis with abscesses formation, emergency open thoracotomy was done with insertion of a chest tube to drain the abscess. Pus culture showed a mixture of bacteria (anaerobic Gram positive bacilli, Peptosstreptococcus species, Prevotella species). However, unfortunately, because of her far advanced infectious condition, progressive multiple organ

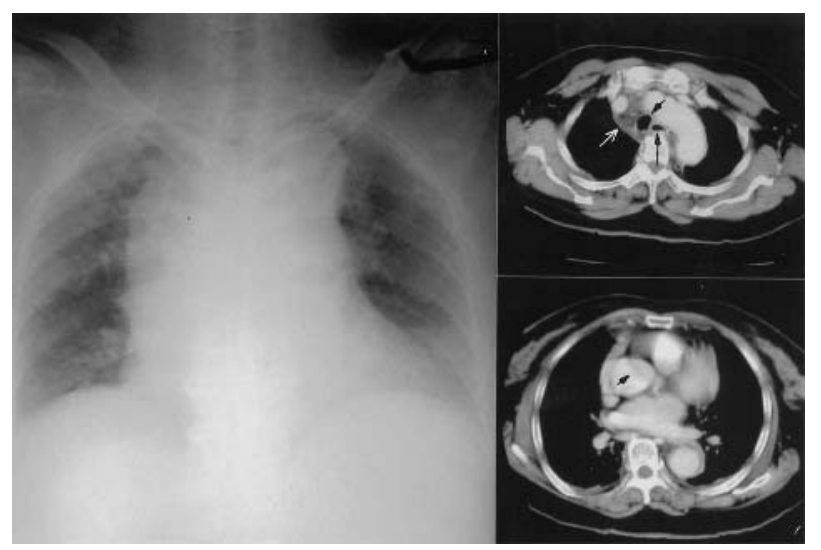

Figure 1 Supine chest film showed widening of mediastinum. Contrast enhanced CT scan of chest showed some increased infiltration and minimal fluid accumulations (white arrow) over mediastinal fat surrounding the tracheal (short arrow) and oesophagus (long arrow). A curvilinear artefact (arrow head) is seen over left anterolateral aspect of ascending aorta in one image at lower level, which was initially misdiagnosed as intimal flap in aortic dissection. 


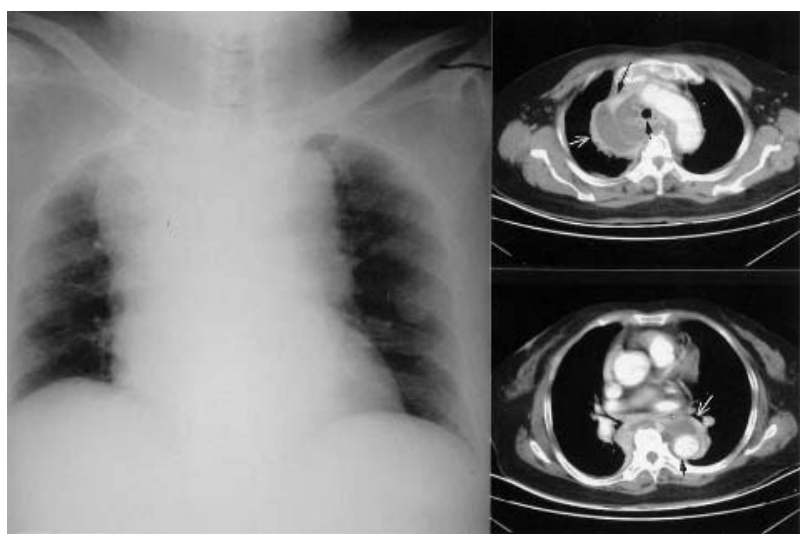

Figure 2 Five days later, the supine chest film showed progressive enlargement of mediastinum. Contrast enhanced CT of chest disclosed noticeable enlargement of mediastinum with multi-loculated abscesses (white arrow) around the trachea (short arrow) and superior vena cava (long arrow), more prominent over the right paratracheal region. The abscesses (white arrow) also extended downward along the descending aorta (small arrow).

failure attributable to sepsis developed and she died on the 20th day after admission to our hospital.

\section{DISCUSSION}

Reviewing the literature, DNM is an uncommon disease. DNM originates most commonly from deep neck infection attribtuable to odontogenic infection. Other causes include peritonsillar abscess, retropharyngeal abscess, etc. ${ }^{148}$ In DNM, patients usually present with neck swelling, chest pain, dyspnea, dsyphagia, and/or respiratory distress. ${ }^{13} 56910$ Delay in diagnosis is commonly noted, leading to the high mortality rates $(40 \%-60 \%)$ in some series. ${ }^{18}$ Traditional radiological examinations might show widening of the mediastinal shadow, widening of the retrovisceral space, increasing thickness of the retropharyngeal, and retrotracheal soft tissue space of neck only in a far advanced condition. ${ }^{4} 811$ Contrast enhanced CT of the chest has been a useful and reliable imaging tool to make the diagnosis. ${ }^{159}{ }^{11}$ Concerning the management, in addition to antibiotics to cover both aerobes and anaerobes, it seems that aggressive operative procedures with standard posterolateral thorocotomy is the most effective treatment. ${ }^{14-689} 9^{12-14}$

In this report, we presented a case of DNM, which originated from tonsillitis and then peritonsillar and retropharyngeal abscess with deep neck and mediastinal extension and misdiagnosed as thoracic aortic dissection because of its main clinical features of chest pain and widening of mediastinum. The possible causes of misdiagnosis stem from unfamiliarity with this rare disease and misreading of the chest CT because of difficulty interpretating mediastinal soft tissue infiltation. Two clinical lessons could be learnt from our case. Firstly, for patients with peritonsillar infection, a commonly encountered disease in ED, inquiry of chest pain and other related clinical presentations might remind clinicians of the possibility of extension of infection into deep neck and mediastinum; and for patients with chest pain, other than the commonly mentioned conditions, a search for the possibility of mediastinal infection is necessary. Chest pain is the common presentation in the extension process of neck infection into the mediastinum, while in the differential diagnoses of chest pain, clinicians usually focus on cardiovascular causes and DNM is rarely mentioned and emphasised. Secondly, familiarity with this disease and clinical correlation in some clinical conditions (especially chest pain, sepsis, respiratory distress, dysphagia, neck swelling associated with oropharyngeal infections) might be the keystone to obtain an earlier diagnosis and a better prognosis. Iyoda et al have reported that the mortality in Japanese cases decreased from 50\% (12 of 24) before 1989 to $21.7 \%$ ( 13 of 60 ) after 1980 because of the improved recognition of DNM. ${ }^{13}$

\section{Authors' affiliations}

S-L Chou, C-H Chern, C-K How, L-M Wang, C-H Lee, Department of Emergency Medicine, Veterans General Hospital-Taipei, National YangMing University, Taiwan, ROC

J-D Chen, Department of Radiology, Veterans General Hospital-Taipei

Correspondence to: $\operatorname{Dr} \mathrm{C}-\mathrm{H}$ Chern, Department of Emergency Medicine, Veterans General Hospital-Taipei, Taiwan, ROC (112);

chchern2002@yahoo.com.tw

Accepted for publication 10 July 2003

\section{REFERENCES}

1 Haraden BM, Zwemer FL Jr. Descending necrotizing mediastinitis: complication of a simple dental infection. Ann Emerg Med 1997;29:683-6.

2 Valat $P$, Pellerin C, Cantini O, et al. Infected mediastinitis secondary to perforation of superior vena cava by a central venous catheter. $\mathrm{Br} J$ Anaesth 2002;88:298-300.

3 Zirkin WM, Nadel ES, Brown DFM. Recurrent pleuritic chest pain. J Emerg Med 1999; 17:329-32.

4 Marty-Ane $\mathrm{CH}$, Berthet JP, Alric $\mathrm{P}$, et al. Management of descending necrotizing mediastinitis: an aggressive treatment for an aggressive disease. Ann Thorac Surg 1999;68:212-17.

5 Sabers CJ, Levy NT, Bowen JM. 33-year-old man with chest pain and fever Mayo Clin Proc 1999:74:181-4.

6 Watanabe M, Ohshita Y, Aoki T, et al. Empyema and mediastinitis complicating retropharyngeal abscess. Thorax 1994;49:1 179-80.

7 Weesner CL, Cisek JE. Lemierre syndrome: the forgotten disease. Ann Emerg Med 1993;22:255-8.

8 Estrera AS, Landay MJ, Grisham JM, et al. Descending necrotizing mediastinitis. Surg Gynecol Obstet 1983;157:545-52.

9 Marty-Ane CH, Alauzen M, Alric P, et al. Descending necrotizing mediastinitis. J Thorac Cardiovasc Surg 1994;107:55-61.

10 Sakamoto H, Aoki T, Kise Y, et al. Descecnding necrotizing mediastinitis due to odontogenic infections. Oral Surg Oral Med Oral Pathol Oral Radiol Endod 2000;89:412-19.

11 Yang X, Soimakallio S. The role of different imaging procedures in early diagnosis and management of descending necrotizing mediastinitis. Eur Arch Otorhinolaryngol 1996;253:316-17.

12 Baumgartner FJ, Omari BO, Klein SR. Appropriate exposure and drainage for descending necrotizing mediastinitis. Ann Thorac Surg 1997:64:887-8.

13 lyoda A, Yusa T, Fujisawa T, et al. Descending necrotizing mediastinitis: report of a case. Surg Today 1999;29:1209-12.

14 Wheatley MJ, Stirling MC, Kirsh MM, et al. Descending necrotizing mediastinits: transvervical drainage in not enough. Ann Thorac Surg 1990;49:780-4. 


\title{
A case of thoracic aortic dissection presenting as lateral pleuritic chest pain
}

\author{
H S H Hado, J H B Scarpello, T Barton, H Scarborough, T A Elhadd
}

Emerg Med J 2005;22:229-230

An unusual presentation of thoracic aortic dissection in a 73 year old man is described. He was admitted to hospital with severe left sided pleuritic chest pain. Examination on admission was normal apart from minor tenderness on palpation of the left lower chest wall. Chest $x$ ray showed cardiomegaly with right lung shadowing, and ventilation/ perfusion scan was negative. Spiral computed tomography done on the fourth day showed a false lumen on the ascending aorta. He underwent surgery but deteriorated postoperatively because of intrathoracic bleeding and developed cardiac tamponade from which resuscitation was not possible.

$\mathrm{T}$ horacic aortic dissection may present in several ways and requires a high index of suspicion, ${ }^{12}$ as any delay in diagnosis may prove disastrous. It is rare for dissection to present with pulmonary symptoms. Samuel and Goldburgh ${ }^{3}$ reported four cases who were thought to have pneumonia antemortem but who were found at necropsy to have aortic dissection. We describe a patient who presented with clinical and radiological features suggestive of infective exacerbation of chronic bronchitis or pulmonary embolism but who was found to have aortic dissection.

\section{CASE REPORT}

A 73 year old man with a history of chronic bronchitis secondary to heavy smoking, ischaemic heart disease, and hypertension was admitted to hospital with a two day history of left sided pleuritic chest pain. Two weeks earlier, he developed breathlessness on exertion, fever, and a productive cough not responding to antibiotics. On admission he complained of severe left sided lateral chest pain, aggravated by cough and deep breathing.

On examination he was pale and dyspnoeic with a sinus bradycardia of 55 beats/min, blood pressure of 143/73 $\mathrm{mm} \mathrm{Hg}$, and tenderness at the left lower chest wall but no other abnormality. An ECG showed old anterolateral ischaemia and sinus bradycardia, and chest $x$ ray showed cardiomegaly, prominence of the aortic knuckle, unfolding of the descending aorta, and linear atelectasis at the right lung base with pleural thickening. Haematological and biochemical profiles were normal apart from mild renal impairment (plasma creatinine $185 \mu \mathrm{mol} / \mathrm{l}$ ). Arterial blood gases showed only hypoxaemia $\left(\mathrm{PO}_{2} 8.41 \mathrm{kPa}\right.$, $)$ so a ventilation/perfusion scan (V/Q scan) was requested; this was done 48 hours after admission but was negative. The patient was treated with oxygen, heparin, simple analgesics, and antibiotics. He remained haemodynamically stable over the following 24 hours and made some improvement but his lateral chest pain was increasing, requiring stronger analgesics. Spiral computed tomography of the chest was then carried out to exclude pulmonary embolism. This showed no evidence of pulmonary embolism but revealed a false lumen in the ascending aorta suggestive of aortic dissection (fig 1). Angiography confirmed dissection of the ascending aorta with minor narrowing of the circumflex artery suggestive of a muscular band.

At operation diffuse pericardial adhesions with moderate left ventricle hypertrophy but normal right ventricle were noted. There was dissection of the ascending aorta one centimetre proximal to the origin of the innominate artery, extending anteriorly and to the left but stopping short of the supra-sinus ridge. The aortic valve was not involved. There was thrombus in the false lumen. The dissection was grafted but the patient deteriorated shortly after surgery because of intrathorcic bleeding and cardiac tamponade. On second exploration, the bleeding was controlled but he died six days later. Necropsy showed hypoxic encephalopathy with oedematous lungs but an intact anastomatic line at the graft site.

\section{DISCUSSION}

The term dissecting aortic aneurysm, which was coined by Laennec in 1819, has been replaced by aortic dissection, as it is rare for a dissecting aorta to become aneurysmal. ${ }^{4}$ Historically, aortic dissection was usually a postmortem diagnosis, and this was attributed to the infrequency of the condition, universal lack of clinical suspicion, limitation of investigations, and the absence of a characteristic syndrome. ${ }^{5}$ Despite the availability of modern radiography, including magnetic resonance imaging, many cases are still misdiagnosed owing to the varied clinical presentation of the condition.

In more than $90 \%$ of cases, aortic dissection usually presents with sudden severe chest pain, which may be described as tearing or ripping in nature. ${ }^{4}$ The pain is often maximal at the time of the onset, and later subsides or remains constant. It is usually very severe; nonetheless many patients may sustain painless aortic dissection. ${ }^{4}$

Our patient presented unusually with left lateral pleuritic chest pain. Kouchoukos and Dougenis ascribed left pleuritic chest pain to thoracic aortic dissection, ${ }^{6}$ although this usually occurs with descending rather than ascending dissection. The presence of hypoxaemia with a history of chronic bronchitis made infection or pulmonary embolism more likely than aortic dissection and this was further supported by the chest $x$ ray findings. Jagannath et al studied the $x$ ray findings of 36 patients with angiographically proven aortic dissection, ${ }^{7}$ and found that widening of the mediastanium and aortic knuckle were the only reliable radiographic features predicting aortic dissection. None of these features was present in our patient.

Patients with aortic dissection usually present with haemodynmic disturbance culminating in circulatory collapse, or with hypertension (which is also a risk factor for aortic dissection) in half to two thirds of cases, especially with distal dissection. The presence of hypotension attributed to rupture of the dissection commonly occurs with proximal dissection. ${ }^{14}$ Compromise of the blood flow to one of the 


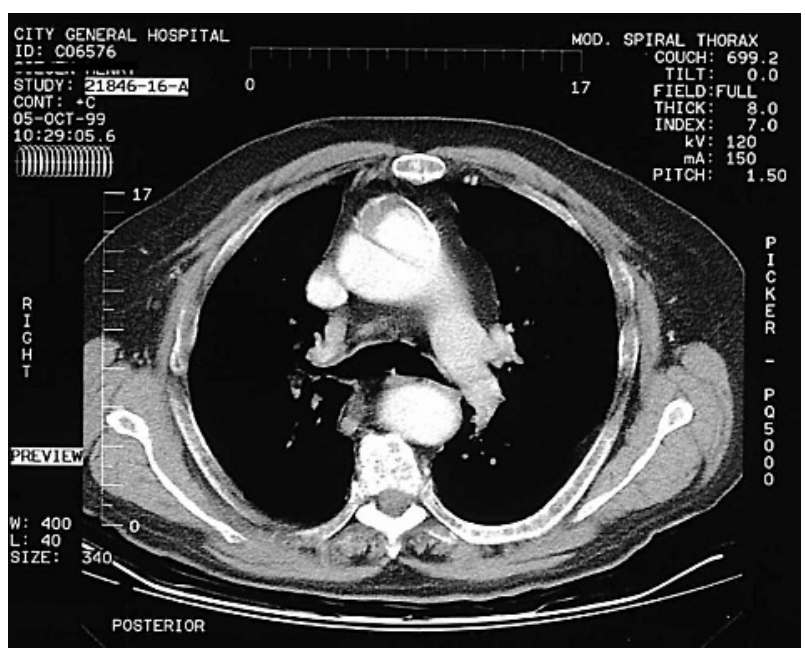

Figure 1 Spiral computed tomography of the chest following angiography.

subclavian arteries may lead to variation in blood pressure between the right and left arms. ${ }^{1}$ This is an invaluable physical sign, which may be missed or ignored. Pulse deficits or absences occur in $50 \%$ of patients with proximal aortic dissection, the brachiocephalic artery being more commonly affected. ${ }^{1}$ This was not detected in our patient although the dissection occurred proximal to the origin of the common brachiocephelic artery.

Although our patient remained hemodynamically stable preoperatively, the poor operative outcome was consistent with a recent finding of Okita et $a l^{8}$ who reported poor operative outcome in patients over 70 years of age compared with those under 70, especially when operated on as an emergency, and in those with preoperative vital organ damage.

Finally our patient was thought to have pulmonary embolism from his clinical presentation, but a V/Q scan was negative. A case of aortic dissection reported by Stollberger et al had a decrease in perfusion on V/Q scan. ${ }^{9}$

\section{Conclusions}

This case highlights the need to consider aortic dissection as a cause of atypical chest pain. This condition may simulate other pulmonary diseases such as pneumonia or pulmonary embolism.

\section{Authors' affiliations}

H S H Hado, T A Elhadd, Department of Endocrinology, Dudley Hospitals NHS Trust, Dudley, West Midlands, UK

J H B Scarpello, T Barton, H Scarborough, Department of Diabetes and Endocrinology, North Staffordshire Hospitals NHS Trust, Stoke-on-Trent, UK

Correspondence to: DrT A Elhadd, Department of Medicine, King Faisel Specialist Hospital and Research Centre, PO Box 40047, Jeddah 21499, Kingdom of Saudi Arabia; tarikelhadd@aol.com

Accepted for publication 9 July 2003

\section{REFERENCES}

1 Eve $\mathbf{E}$, Roman W. The clinical recognition of dissecting aortic aneurysm. Am J Med 1976;60:625-32.

2 Ponraj P, Pepper J. Aortic dissection. Br J Clin Pract 1992;46:127-31.

3 Samuel B, Goldburgh HL. The varied clinical syndromes produced by dissecting aneurysm. Am Heart J 1947:00:198-21 1.

4 De Sanctis RW, Dorghazi RM, Austen WG, et al. Medical progress; aortic dissection. N Engl J Med 1987;317:1060-7.

5 Willius FA, Crogg RW. Cardiac clinic: talk on dissecting aneurysm of the aorta. Mayo Clin Proc 1941;16:41.

6 Kouchoukos NT, Dougenis D. Medical progress: surgery of the thoracic aorta. N Engl J Med 1997;336:1876-89.

7 Jagannath AS, Sos TA, Lockhart SH, et al. Aortic dissection: a statistical analysis of the usefulness of plain chest radiographic findings. Am J Roentgenol 1986;147:1123-6.

8 Okita Y, Ando M, Minatoya K, et al. Early and long-term results of surgery for aneurysm of thoracic aorta in septuagenarians and octogenarians. Eur J Cardiothorac Surg 1999;16:317-23.

9 Stollberger C, Finsterer J, Fonsek C, et al. Headache as initial presentation of acute aortic dissection type A. Cephalogia 1998;18:583-84.

\section{Pneumomediastinum secondary to an apparently trivial stab wound to the neck: the value of the Hamman's sign and thorough radiological investigation}

\section{Enguidanos, A Pfleiderer, W Smith, S Ramkumar}

Perforation of the pharynx and upper oesophagus after stab wounds to the neck is easily overlooked because of the relative lack of symptoms. A case is reported in which pneumomediastinum occurred after an apparently trivial neck wound.

njury to the airway and the major vessels naturally dominates the management in cases of penetrating trauma to the neck. Although the incidence of associated perforation of the pharynx and upper oesophagus is reported to be relatively high, ${ }^{1}$ it is considered infrequently and can easily be overlooked because of the relative lack of symptoms, as demonstrated in this case.

\section{CASE REPORT}

A 25 year old man presented to the A\&E department after having been stabbed in the left posterior triangle of the neck with a stiletto knife. Despite this, he was well and observations on admission-including pulse, blood pressure, and respiratory rate-were all normal and remained stable, 


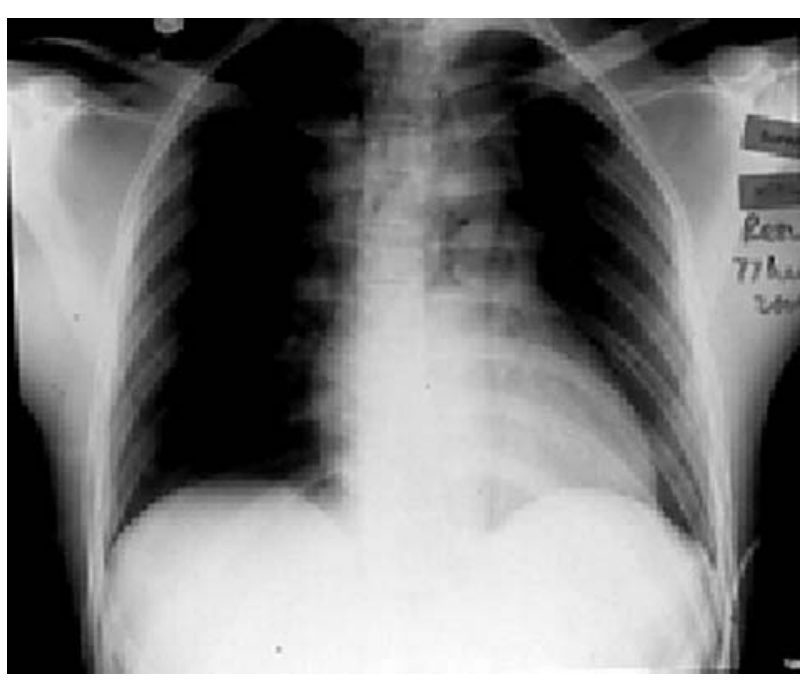

Figure 1 Chest $x$ ray showing extensive pneumomediastinum and Naclerio's V sign.

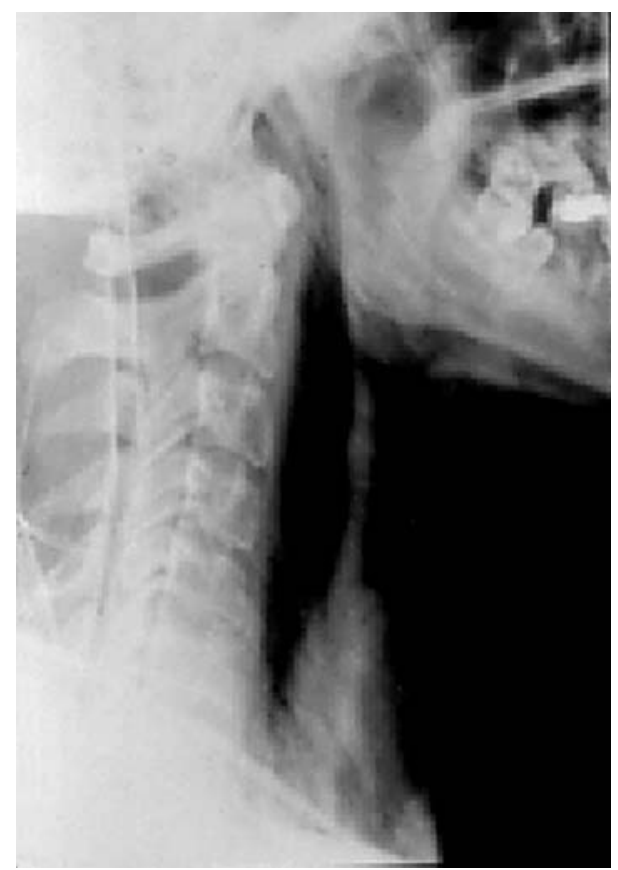

Figure 2 Lateral soft tissue $x$ ray of the neck showing an extensive pocket of retropharyngeal air.

with no sign of any respiratory distress or injury to major vessels. The presence of mild localised surgical emphysema in the posterior triangle was confirmed but there was no evidence of internal injury to the pharynx or larynx or any air escape from the neck wound on respiration. Although clinical examination of the chest did not show any of the usual signs of pneumothorax, auscultation revealed a positive Hamman's sign. This is characterised by a peculiar crunching, bubbling, popping, or crackling sound that varies with the phase of the cardiac cycle and is best heard in the left lateral decubitus position. A positive Hamman's sign usually indicates the presence of a pneumomediastinum but may also be associated with an isolated pneumothorax. ${ }^{2}$

The presence of this sign prompted a chest $x$ ray (fig 1 ). This not only showed the expected subcutaneous emphysema in the soft tissues of the neck, but also the presence of air in the mediastinum outlining the whole of the descending aorta and the superior surface of the diaphragm. At the junction of these two structures, the air formed a " $\mathrm{V}$ " previously described as Naclerio's V sign. ${ }^{3}$ A lateral soft tissue $x$ ray of the neck (fig 2) also showed a large amount of retropharyngeal air, indicating a possible perforation of the pharynx or upper oesophagus, though a subsequent contrast swallow could not demonstrate this. As a result, and because the patient's condition was stable, he was treated conservatively with prophylactic wide spectrum antibiotics. Sequential chest $x$ rays showed a gradual uncomplicated resolution of the mediastinal air and surgical emphysema, which had completely disappeared after six days, when the patient was discharged home well.

\section{COMMENT}

Unsuspected and undiagnosed perforation of the upper aerodigestive tract may have serious consequences and may even lead to death from advanced mediastinitis. Such events might be avoided by early identification of a perforated viscus and if a significant defect had been identified surgical closure to avoid further complications would have been indicated. Early diagnosis has been reported to reduce the associated mortality from $85.7 \%$ to $50 \%{ }^{4}$ Routine radiological investigations-including a lateral soft tissue $x$ ray of the neck, chest $x$ ray, and barium swallow-are recommended in all cases of penetrating neck injury.

\section{Authors' affiliations}

L Enguidanos, A Pfleiderer, W Smith, Edith Cavell Hospital, Peterborough, Cambridgeshire, UK

S Ramkumar, Luton and Dunstable Hospital, Luton, Bedfordshire, UK

Correspondence to: Mr Andrew Pfleiderer, ENT Department, Edith Cavell Hospital, Bretton, Peterborough PE3 9GZ, UK; agpfleiderer@ doctors.org.uk

Accepted for publication 19 August 2003

\section{REFERENCES}

1 Levy RD, Degiannis E, Hatzitheophilou C, et al. Management of penetrating injuries of the cervical trachea. Ann R Coll Surg Engl 1997;79:195-7.

2 Baumann MH, Sahn SA. Hamman's sign revisited: pneumothorax or pneumomediastinum? Chest 1992;102:1281-2.

3 Bejvan SM, Godwin JD. Pnuemomediastinum: old signs and new signs. Am J Radiol 1996; 166:1041-8.

4 Rubikas R, Gradauskas P, Vilcinskas A, et al. Descending necrotizing mediastinitis [abstract]. Medicina (Kaunas) 2002;28:91-3. 


\section{Missed clavicular fracture; inadequate radiograph or occult fracture?}

\section{Alao, H R Guly}

$\mathrm{F}$ ractures of the clavicle are extremely common accounting for $5 \%-10 \%$ of all fractures. ${ }^{1}$ It is well recognised that the initial radiograph may be negative in children and such children often present at a later date with a complaint of a palpable lump in the region of the clavicle. This has led to the practice of treating all clinically fractured clavicles with a normal radiograph as a fracture. ${ }^{2}$ A search of the English literature and standard orthopaedic text failed to find such a recommendation for adults. We present a case series of three adults who had a normal initial radiograph of the clavicle after trauma and who subsequently had a fracture verified at re-presentation.

\section{CASES}

Over a two year period the authors were involved in the management of three adult patients who were suspected of fractured clavicle on clinical grounds but whose initial anterior-posterior (A-P) radiographs were normal. The patients re-presented within two weeks with persistent symptoms and repeat radiographs showed fractured clavicle. All three patients had a fracture of the mid-shaft of the clavicle (see table 1 and fig 1 ).

\section{DISCUSSION}

Occult fracture is well described in the hip and the scaphoid and failure to recognise this could lead to serious consequences. While clavicular fracture is often viewed as benign, it is important for patients to be aware if they have a fracture as it has implications on expected time of recovery and when they can return to work. In addition complications such as non-union do occur and inadequate initial immobilisation is a common cause. ${ }^{3}$ Two views of the clavicle, A-P and $45^{\circ}$ cephalic tilt were advocated by Widner ${ }^{5}$ however, it is the standard practice in most radiology departments to produce a single A-P view. In addition the standard exposure for the shaft of clavicle over exposes the lateral third of the clavicle while the medial third is often obscured by overlapping ribs, vertebral, and mediastinal shadows. All our patients had a single A-P view radiograph. It is possible that these fractures would not have been missed had a $45^{\circ}$ cephalic tilt view been obtained. Clinicians should be aware that some clavicular fractures will be occult in the standard
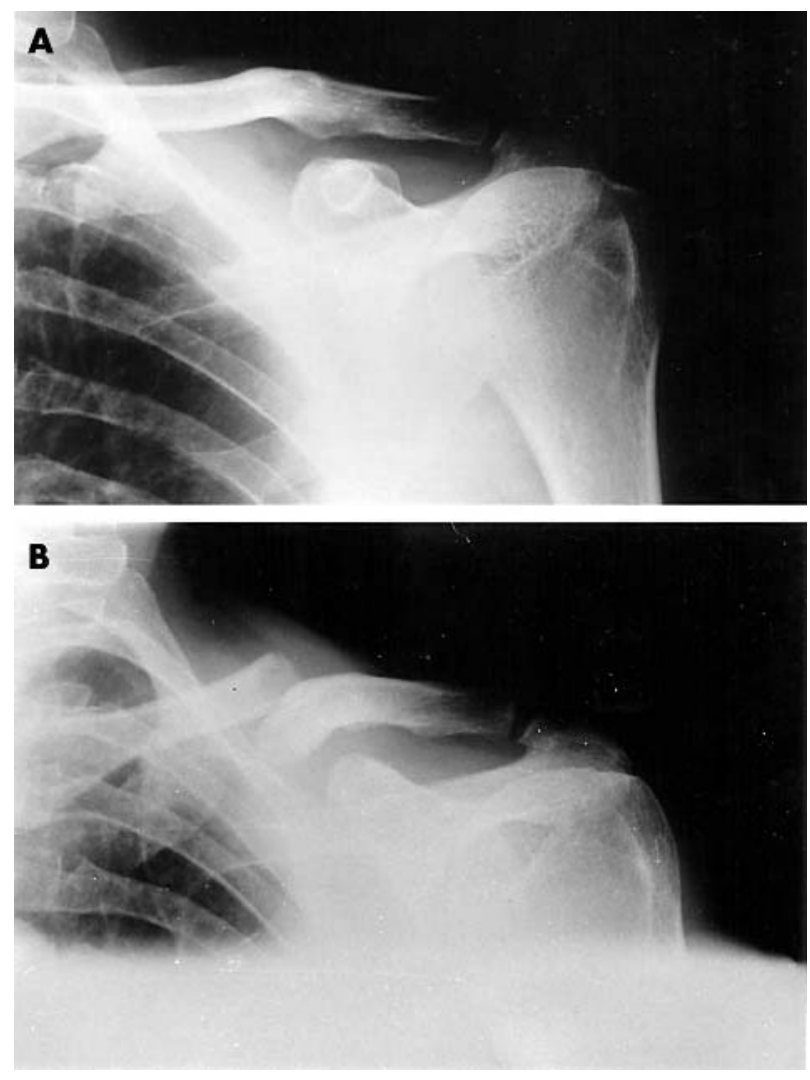

Figure 1 Initial radiograph with no fracture visible (A) and the same radiograph a week later showing a fracture (B).

A-P view. We therefore recommend that if there is a strong clinical suspicion of a fracture of the clavicle further views should be obtained. If radiographs remained negative the patient should be treated as though there was a fracture and this possibility must be communicated to the patient. Patients with a strong clinical suspicion of a fracture should be asked to re-attend in about 10 days, if symptoms persist,

\begin{tabular}{|lllll|}
\hline Table 1 & Patient characteristics & & \\
\hline Age $(\mathbf{y})$ & Sex & Mechanism & $\begin{array}{l}\text { Time of second } \\
\text { radiograph (days) }\end{array}$ & Site of fracture \\
\hline 63 & Male & Fall from a bike & 5 & Mid-shaft \\
19 & Female & Fall from motorbike & 11 & Mid-shaft \\
27 & Male & Fall from a bike & 7 & Mid-shaft \\
\hline
\end{tabular}


for a repeat radiograph as is commonly practised for fractured scaphoid.

\section{Authors' affiliations}

D Alao, H R Guly, Accident and Emergency Department, Derriford Hospital, Plymouth, UK

Correspondence to: Mr D Alao, Accident and Emergency Department, Derriford Hospital, Plymouth PL6 8DH, UK; Aalao2@aol.com

\section{REFERENCES}

1 Simpson NS, Jupiter JP. Clavicle non-union and malunion: evaluation and surgical management. J Am Acad Orthop Surg 1993;4:1-8.

2 Rockwood and Green's fractures in adults. 3rd ed. Philadelphia: J B Lippincott, 1991:949.

3 Yates DW. Complications of fractures of the clavicle. Injury 1976;7:189-93.

4 Jones GL, McCluskey GM 3rd, Curd DT. on-union of the fractured clavicle: evaluation, aetiology, and treatment. J South Orthop Assoc 2000;9:43-54

5 Widner LA, Riddewood $\mathrm{HO}$. The value of the lordotic view in diagnosis of fractured clavicle. Int Radiol 1980;5:69-70. 